\title{
Identifying power line harmonic radiation from an electrical network
}

\author{
S. M. Werner, C. J. Rodger, and N. R. Thomson \\ Department of Physics, University of Otago, Dunedin, New Zealand
}

Received: 11 January 2005 - Revised: 24 March 2005 - Accepted: 20 June 2005 - Published: 15 September 2005

\begin{abstract}
It has been suggested that the space environment is being polluted by power line harmonic radiation (PLHR), generated from harmonics of the electrical power transmission frequency $(50$ or $60 \mathrm{~Hz})$ and radiated into the ionosphere and magnetosphere by long power lines. While some insitu satellite measurements of PLHR have been reported, it has proved difficult to confirm the source and overall significance. The electricity network of the city of Dunedin, New Zealand, is tiny compared to the many large industrial zones found outside New Zealand. However, the $1050 \mathrm{~Hz}$ ripple control signal injected into the local electrical grid at regular intervals as a load-control mechanism provides an opportunity for identifying PLHR strengths radiated from a spatially well defined electrical network. In-situ observations by satellites should allow a greater understanding of PLHR and its significance as man-made pollution to nearEarth space. Calculations have been undertaken to estimate the strength of the radiation fields expected from the ripple control signal which is injected into the Dunedin city electrical network. We find that ground-based measurements will not be sensitive enough for detection of the ripple control radiation fields, even during the quietest winter night. While significant power penetrates the lower ionosphere, this is well below the reported threshold required for nonlinear triggering in the Van Allen radiation belts. Some radiated fields at satellite altitudes should be detectable, allowing insitu measurements. At the altitude of the DEMETER mission, the radiated electric fields will not be detectable under any ionospheric conditions. However, we find that the radiated magnetic fields may be detectable by the DEMETER satellite at certain times, although this will be very difficult. Nonetheless, there is the possibility for future experimental campaigns.
\end{abstract}

Keywords. Magnetospheric physics (Magnetosphereionosphere interactions; Plasma waves and instabilities) Ionosphere (Active experiments)

Correspondence to: C. J. Rodger

(crodger@physics.otago.ac.nz)

\section{Introduction}

There are experimental reports indicating that radio waves from long electrical transmission lines may leak into nearEarth space and modify the space environment (e.g. Bullough, 1995; Parrot and Zaslavski, 1996). Radio waves in the very low frequency (VLF, 3-30 kHz) and extremely low frequency (ELF, 3-3000 Hz) bands can interact with cyclotron resonant Van Allen radiation belt electrons near the equatorial zone. One consequence of these interactions is the pitch angle scattering of energetic radiation belt electrons driving some resonant electrons into the bounce loss cone (Walt, 1994), and resulting in their precipitation into the atmosphere (Rycroft, 1973). Both natural and man-made lowfrequency radio waves are important here, including wave sources located at the Earth's surface and those in the space surrounding the Earth (Abel and Thorne, 1998). Examples of near-Earth sources are the strong radio pulses generated by lightning as well as transmissions from man-made communications stations. In these cases most of the wave's energy is trapped between the Earth and the lower boundary of the ionosphere (Wait, 1996). A percentage of the wave energy penetrates the ionosphere and enters near-Earth space where it may interact with particles in the Van Allen belts. While the physical process through which the waves and particles interact is well understood (e.g. Tsurutani and Lakhina, 1997), there is significant uncertainty as to the relative importance of different wave sources in different spatial regions of the belts at different times and over different energy ranges (Walt, 1996). Essentially, the complexity of the system is such that it has proved extremely difficult to draw global conclusions from point-satellite measurements and case studies.

In most parts of the world, electricity is transmitted as AC (alternating current) at a nominal frequency of 50 or $60 \mathrm{~Hz}$. However, distortions in the electricity waveforms from nonlinear loads lead to significant harmonics of $50 / 60 \mathrm{~Hz}$ (up to several kilohertz) in the transmission lines. Nonlinear electronic devices used in computers and electronic load controllers are two of the greatest causes of harmonic distortion in electrical supply networks (Stebbins, 1996). These 

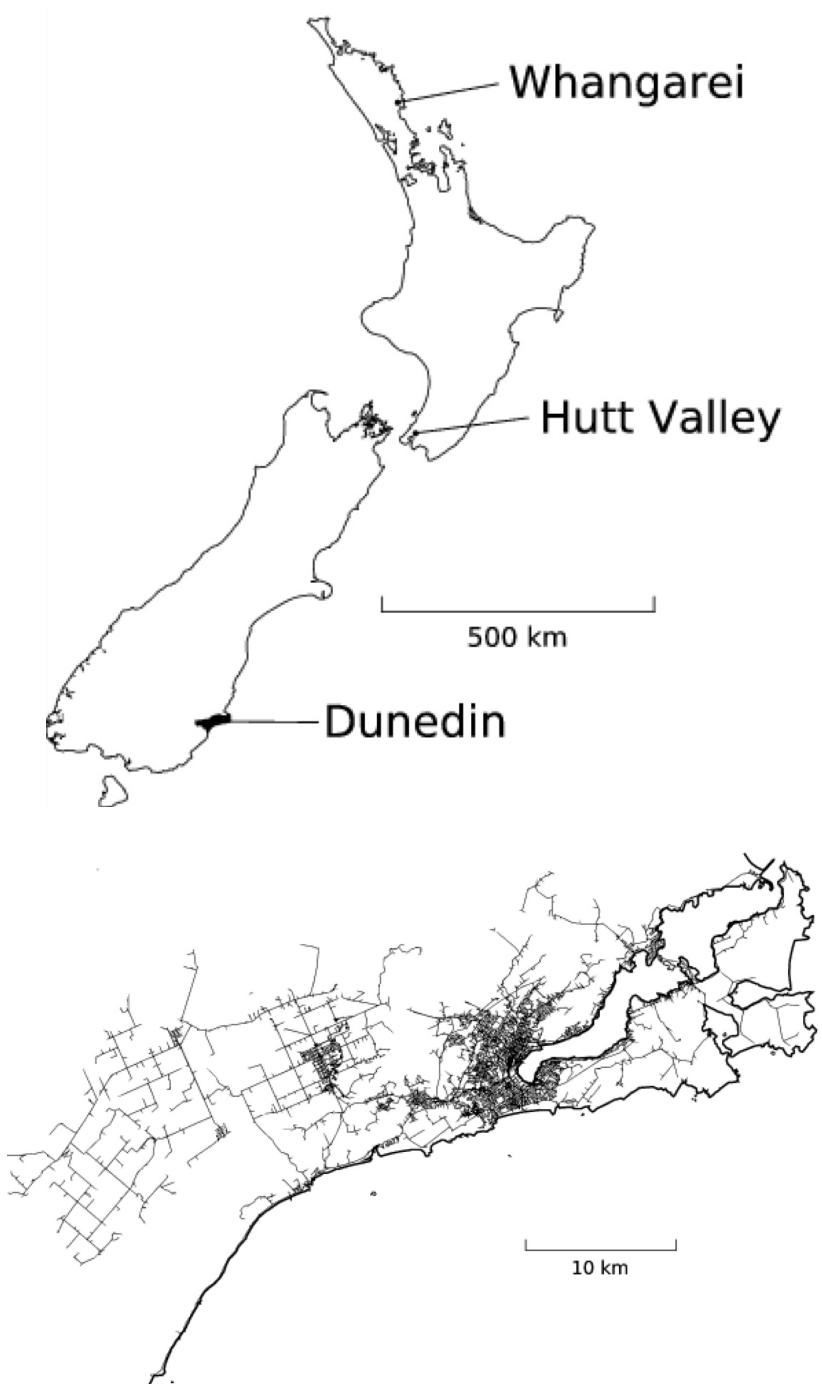

Fig. 1. Map of New Zealand on the left showing the location of Dunedin and other electrical suppliers using a $1050 \mathrm{~Hz}$ ripple control signal. Dunedin's electrical network is shown in detail on the right.

harmonics can be efficiently radiated by long transmission lines, producing power-line harmonic radiation (PLHR). While some experimental reports have indicated that PLHR is currently an important influence on near-Earth space (e.g. Parrot et al., 1991) this has been disputed by other studies (e.g. Higuchi et al., 1986), including those focused at North American longitudes where power consumption is very high (Rodger et al., 2000).

An experimental VLF transmitter located in Antarctica has previously been used to simulate the PLHR in near-Earth space. These experiments indicated a radiated power threshold of $\sim 1 \mathrm{~W}$ (Helliwell et al., 1980), where higher powers lead to the observation of nonlinear triggered emissions (Park and Chang, 1978) indicating strong interactions between waves and trapped particles. While it seems likely that PLHR is not currently significant to geospace in general, we expect electrical power consumption to grow world-wide and the harmonic content in transmission lines to grow faster still, hence increasing PLHR levels. By the year 2000 it was estimated that upward of $60 \%$ of all electricity used in the United States would first pass through an inherently nonlinear semi-conducting device, compared with 40\% in 1996 (Stebbins, 1996). At some stage in the future it seems likely that the harmonic levels on typical high-power transmission lines will pass through the threshold beyond which PLHR becomes a significant pollutant.

However, it is not trivial to estimate the radiated power from a realistic network of power lines. While some insitu satellite measurements have been made, it is difficult to exactly locate the source of the radiation coming from the ground. For example, Ohzora satellite observations appeared to include Japanese PLHR at 50 and $60 \mathrm{~Hz}$ (Tomizawa and Yoshino, 1985). This identification was possible due to the mixed nature of the Japanese electrical grid, where $50 \mathrm{~Hz}$ is used in the northern "half" of the country, and $60 \mathrm{~Hz}$ in the south. However, these authors cautioned that more studies should be conducted to confirm this observation, due to the difficulties of associating any $50 / 60 \mathrm{~Hz}$ signal with a specific region.

In our study we calculate the radiation fields due to the Dunedin ripple control signal. Ripple control is a simple and effective method used to regulate electrical power usage and has been used world wide for at least 50 years (Rennie, 1989). In New Zealand ELF/VLF ripple control tones are injected into regional networks at various times of day to control the electrical load in the network (for residential users this is primarily domestic hot water heating). For example, Dunedin Electricity injects a $1050 \mathrm{~Hz}$ signal, on top of the $50 \mathrm{~Hz}$ carrier frequency, into the Dunedin city network (Dunedin City Council, 1971) which will produce $1050 \mathrm{~Hz}$ radiation, some of which will leak into space. The Dunedin Electricity ripple control signal provides the potential for active transmissions to Earth orbiting satellites from a spatially well defined electrical network, and hence a test on manmade pollution to near-Earth space. The identification of $1050 \mathrm{~Hz}$ signals in satellite observations above Dunedin city during ripple control injection times would allow the clear identification of PLHR from a known source. In this paper we examine the calculated radiated fields expected from the ripple control signal in the Dunedin city electrical network at ground level, the base of the ionosphere, satellite level and in the equatorial plane in the magnetosphere. Our primary goal is to examine the expected signal strength at satellite altitudes, and contrast these with the detection thresholds of in-situ observational missions.

\section{Dunedin electrical network}

\subsection{Ripple control signal}

Since 1959 the city of Dunedin $\left(-45.9^{\circ} \mathrm{S}, 170.5^{\circ} \mathrm{E}, \mathrm{L}=2.76\right)$, New Zealand (Fig. 1) has used "ripple control" for electrical load control by controlling domestic hot water heating and 
street lighting (Dunedin City Council, 1971). Ripple control operates using a tone generator that injects a $1050 \mathrm{~Hz}$ control signal directly into the power transmission lines, while relay devices receive and interpret the signal. Relays for hot water control are located at the electricity consumers' premises and street lighting relays are dispersed along the streets.

At the time of writing, two other New Zealand electricity suppliers are using ripple control at a carrier frequency of $1050 \mathrm{~Hz}$. These are Whangarei and Hutt Valley electricity suppliers and are both relatively far $(>500 \mathrm{~km})$ from Dunedin (Keith Moffat, personal communication, 2003), hence should not interfere with any observational campaign.

The $1050 \mathrm{~Hz}$ ripple control signal is injected into each electrical sub-network at 18 substations distributed throughout Dunedin. Each of the 18 injectors operates simultaneously, each typically injecting $42 \mathrm{~A}$. However, the ripple currents in each sub-network are not injected in-phase relative to the other sub-networks (private communication, Keith Moffat, 2003). It is planned that the Dunedin $1050 \mathrm{~Hz}$ carrier frequency will be progressively replaced with a lower frequency of $317 \mathrm{~Hz}$, from about 2006 .

The ripple control signal begins with a $5 \mathrm{~s}$ start tone to capture the attention of the relays, as shown in Fig. 2. The total control signal lasts $170 \mathrm{~s}$ and is broken into $7.5 \mathrm{~s}$ time windows, activating any of the 22 possible on or off switch commands. Modern relays have shorter time windows, hence more commands can be "squeezed" into each $7.5 \mathrm{~s}$ time window. This can be seen from $\sim 21.5-26.0 \mathrm{~s}$ in Fig. 2. The relays are programmed to control various devices that require switching. In general, Dunedin control signals are injected so hot water heaters are on from at least 1330 LT to 1630 and from 2300 to 0700 LT. During periods of high electricity use these times can be altered and additional ripple control injections occur to switch domestic and industrial equipment. In contrast the control of street lighting is dependent on local lighting levels at the time. The injectors cannot operate more than three times each hour due to overheating problems (private communication, Keith Moffat, 2003).

\subsection{Dunedin electrical network model}

To model the radiation fields produced by the ripple control signal in the Dunedin electrical grid a realistic model of the electrical network is required. However, because of time and computational constraints, including a complete representative model of the entire Dunedin network is unrealistic. We therefore choose to model only the network surrounding a single substation, near Outram, a rural farming area lying on flat land just over $20 \mathrm{~km}$ West of Dunedin's city centre. The entire Dunedin power network stretches from Aromoana, $\sim 20 \mathrm{~km}$ North East of the city centre, to the Taieri River Mouth $\sim 30 \mathrm{~km}$ South-West (Fig. 1). The Outram network has a greater area and lower density in comparison with other substation zones in the Dunedin network, making it simpler to model.

In our Outram model we approximate each power transmission line as a horizontal electric dipole with current mo-

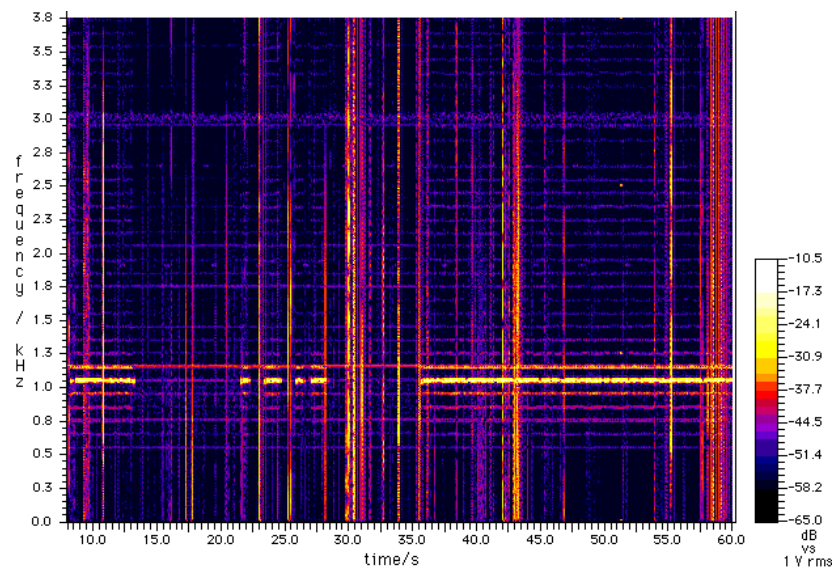

Fig. 2. The first $60 \mathrm{~s}$ of the ripple control spectrum taken from a loop antenna on Swampy Summit (Dunedin). The signal starts at 16:30:08 NZLT on 9 April 2003. Frequencies below $500 \mathrm{~Hz}$ have been filtered, as a strong harmonic exists at $300 \mathrm{~Hz}$.

ment $\mathrm{Il}$. The standard minimum height of above-ground electrical power lines in New Zealand is $4.0 \mathrm{~m}$ to $5.5 \mathrm{~m}$ (NZECP, 1993). However, for simplicity, we place each dipole in our model at ground level. Numerical experimentation shows this makes little difference to the final result.

New Zealand's electrical power is delivered to consumers using 3-phase, typically by four transmission lines, three load carrying lines and a neutral line. Most consumers' premises require only single phase power and thus connect between one of the load carrying transmission lines and the neutral line (Jenneson, 1987). In an ideal system the phase difference between each of the load carrying transmission lines should be $120^{\circ}$, with the neutral line carrying no current. In reality, there is generally some kind of imbalance, often due to one of the load carrying transmission lines supplying more consumers than the other lines. Unbalanced lines are the primary cause of radiated electromagnetic fields.

The momentary imbalance in power lines can reach $15 \%$ (Farrel et al., 1998), particularly when large electrical appliances are switched. However, we employ an imbalance of $8 \%$ for the ripple control currents across the whole Outram model. This is based on observations of the electrical current readings across the 3-phases that were made during a visit to a ripple control injector plant at the Ward Street substation which supplies power to a highly industrial zone inside Dunedin city. This is also based on the fact that the ripple control signal is injected across all three phases each with, ideally, a $120^{\circ}$ phase difference (private communication, Keith Moffat, 2003).

Ideally the unbalanced current will return on the neutral line. In this ideal situation the radiation fields from all three phase lines and the neutral line will almost completely cancel-out. However, there are some imperfections in the electrical system that cause the current to travel back to the source via other paths, such as through the ground. Most of the electrical current flows back along the neutral line, and 

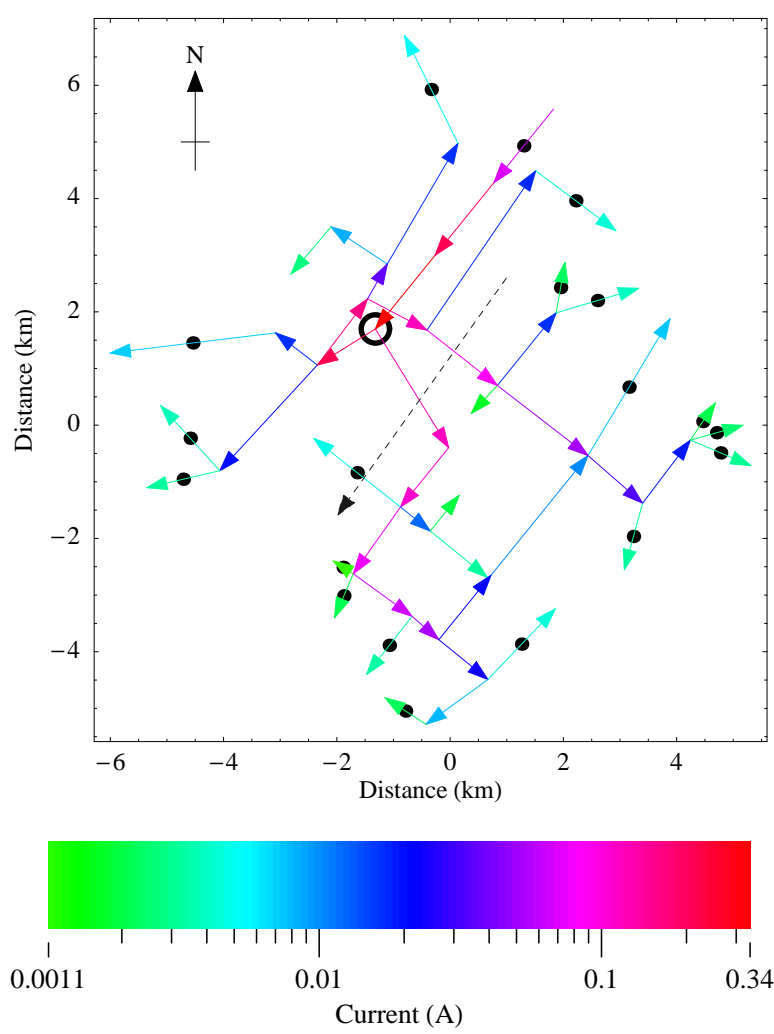

Fig. 3. Our scale model of the Outram network. Each line represents an electrical transmission line, with arrows indicating the sense and direction of the current phase relative to the injection current located at the circle. The black dots indicate terminating capacitors. The dashed line is the dipole approximation of the Outram network. Compare with Fig. 1, where the Outram sub-network lies on the far left of the Dunedin network.

not in a ground return path. Nonetheless it is these ground return currents which will provide the most significant radiated fields. We estimate these losses to be about $10 \%$, in addition to, and similar to the 3-phase imbalance. Hence we assume only $10 \%$ of the $3 \mathrm{~A}$ unbalanced current radiates, and use this in our calculations, equivalent to a $0.3 \mathrm{~A}$ unbalanced ripple control current injected at $230 \mathrm{~V}$ into our model. Note that this is considerably larger than the $1 \mathrm{~mA}$ unbalanced earth-return current found at $1 \mathrm{kHz}$ for a long power line in Newfoundland (Yearby et al., 1983). The Newfoundland line studied had harmonic contents of order 1 part in $10^{6}$, about 2500 times smaller than that found in a typical New Zealand context (EASEINZ, 1989). We suggest this is due to the difference between a dense urban network and a long distance power transmission line.

We queried a Graphical Information System (GIS) database to obtain the orientation of each transmission line segment for our Outram model (private communication, Keith Moffat, 2003). Line segments shorter than approximately $100 \mathrm{~m}$ are ignored, due to their limited radiating capability. Fig. 3 shows the 49 line segments used in our Outram model.

\subsection{Currents in the Outram model}

We model the 3-phase transmission lines by using single wires to carry the $0.8 \%$ imbalanced current, as discussed in the previous section. To allow the simulated ripple control current to flow across the full extent of the model, we place $1 \mu \mathrm{F}$ capacitors at the outer extremities of the Outram model, shown by the dots in Fig. 3. We employ the computer program Numerical Electromagnetics Code (NEC-2), documented by Burke and Poggio (1977), to calculate the distribution of currents in our Outram antenna/electrical grid model.

The Outram model is then excited with a $1050 \mathrm{~Hz}, 0.3 \mathrm{~A}$ current at the injection point. The directions of the NEC-2 calculated currents produced by this excitation at the injection point are shown by the circle in Fig. 3. As expected, the largest currents are present near the injection point with smaller currents at the extremities of our model. These currents radiate fields that couple into the Earth-ionosphere wave-guide.

We further approximate the Outram model to just a single dipole antenna, loaded with the driving current. The dipole approximation is shown as the dotted line in Fig. 3, with the relative sense shown by the arrow. This dipole approximation, carrying $0.3 \mathrm{~A}$ and $5.1 \mathrm{~km}$ long, is found by averaging the current moments of the whole Outram electrical network. A full 3-dimensional numerical comparison between the full model of all 49 currents and the dipole approximation was made using NEC-2. Excellent agreement was found between the two in all directions, including the azimuthal direction.

\section{Modelling the ripple control signal radiation fields}

The conducting ground and lower boundary of the ionosphere create a waveguide for electromagnetic waves in the ELF/VLF range, which must be taken into account for propagation distances greater than approximately $90 \mathrm{~km}$ (Wait, 1996; Cummer, 2000). For our $1050 \mathrm{~Hz}$ frequency only a few of the lowest waveguide modes will propagate within the waveguide, as the rest of the modes attenuate rapidly.

In our study only two extremes of ionospheric conditions will be considered, represented by the two solstice days of the year. These are the southern hemisphere's midday summer solstice near 21 December and midnight winter solstice near 21 June. Conditions for the rest of the year will fall between these two extremes.

To calculate the radiated fields within the EarthIonosphere waveguide we use the Finite Difference Time Domain (FDTD) method as described by Sullivan (2000). Other methods for calculating the radiation fields inside the Earth-Ionosphere waveguide are available, such as mode theory (Budden, 1961; Wait, 1996), but these methods break down for ELF waves when calculations are made close to the source dipole. Cummer (2000) provides a detailed comparison between mode theory and the numerical FDTD method for ELF-VLF wave propagation in the Earth-Ionosphere 
waveguide cavity. His comparison showed that the FDTD method has very good agreement with mode theory as formulated by Wait (1996).

We use the FDTD method in three-dimensional Cartesian form, with a fine spatial step of $8500 \mathrm{~m}$ in the two horizontal directions and $700 \mathrm{~m}$ in the vertical direction. The vertical spatial step is to incorporate the existence of Earth return currents, which were approximated by placing an equal and opposite return current below the surface of the ground. For $1050 \mathrm{~Hz}$ and Outram ground conditions, the mean return current will lie at a depth of about $700 \mathrm{~m}$ (e.g., Bullough, 1995). Since we have a three-dimensional grid, we use all three components of the electric and magnetic fields. No absorbing boundary conditions were used, instead the spatial grid was made large enough to allow the simulation to reach a steady state without interference from the boundaries.

We use the same FDTD method as Cummer (2000) and treat the ionosphere as a isotropic conductor, using a vertical conductivity profile (private communication, World Data Centre for Geomagnetism, 2003). However, this is not suitable to model propagation through the ionospheric plasma, which would require more advanced FDTD methods (for one-dimensional wave propagation see (Young, 1994)). The ground properties are representative of this part of New Zealand, with a relative dielectric constant of $\epsilon=12.0$ (Kraus, 1988) and conductivity $\sigma=10^{-3} \mathrm{~S} \mathrm{~m}^{-1}$.

We use NEC-2 to calculate the radiation pattern of the entire 49 current Outram model and compare this result to the single dipole approximation using the FDTD method, neglecting the ionosphere. We also verified our far-field FDTD results using the method as described by Wait (1996). This shows that the proven techniques for calculating the radiated fields agree with those we find in this case, giving us confidence in our FDTD method.

\section{Field calculation results}

Having calculated the radiation fields from the Outram electrical network model we extrapolate the field data to approximate the radiated power for the entire Dunedin network. There are 18 substations that inject the ripple control signal into the Dunedin electrical network. Hence, we scale the total radiated power from Outram by 18 to get the total radiated power for Dunedin. Note that this may somewhat over estimate the total radiated power as line lengths in Outram are relatively long compared to other substation zones in the Dunedin electrical network. However, there should be some compensation due to the higher density of lines in urban Dunedin in comparison with a rural part of Dunedin like Outram.

Using the above approximation we can estimate the radiation fields due to the entire Dunedin ripple control signal at ground level, the base of the ionosphere, satellite level and

\footnotetext{
${ }^{1}$ (private communication, Malcolm Ingham, Victoria University)
}

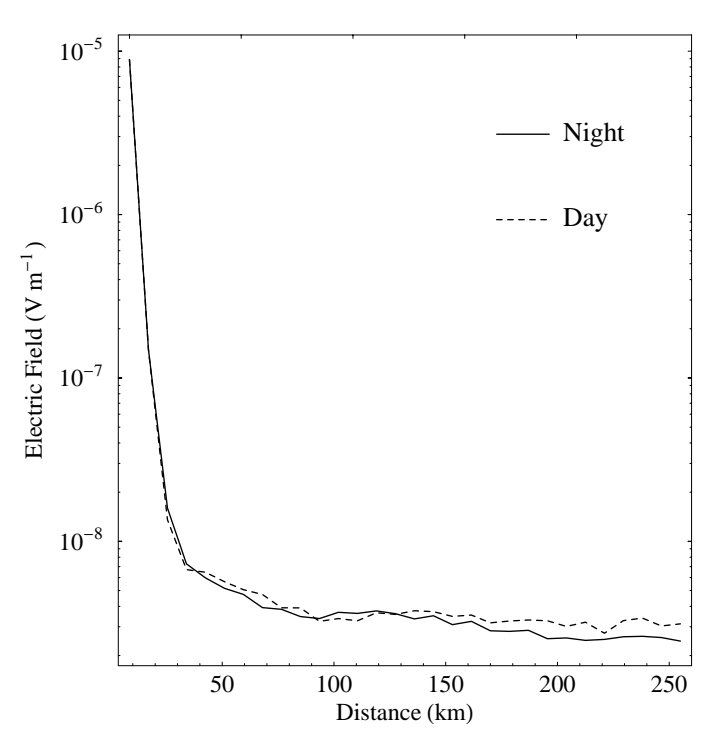

Fig. 4. The day and night electric field magnitudes at ground level, at a bearing of $40^{\circ}$ from North, with increasing distance from Dunedin.

near the geomagnetic equatorial region where wave-particle interactions occur.

\subsection{Calculated fields below the ionosphere}

For the ripple control radiation fields to be measurable at the ground they must be above the local background noise. Much of the naturally occurring background noise inside the waveguide at ELF/VLF frequencies is due to lightning discharges, which tend to occur over land masses during local late afternoon hours. The noise in local summer is typically higher than local winter (Smith, 1995). Typical "natural" noise levels at $1 \mathrm{kHz}$ for the New Zealand region are $10 \mu \mathrm{Vm}^{-1} \mathrm{~Hz}^{-\frac{1}{2}}$ and $0.3 \mu \mathrm{Vm}^{-1} \mathrm{~Hz}^{-\frac{1}{2}}$ for summer day and winter afternoon/evening (1600-2000 LT), respectively (Watt, 1967). Although our calculations are based on the winter midnight ionosphere, there is little difference in electron density between midnight and at 2000 LT (see Bilitza, 2001). These noise values agree with measurements made by Barr (1979) at midday near the end of summer in areas close to Dunedin. Any measurements of the Dunedin ripple control radiation will need to be taken sufficiently far away from all power lines such that local power line harmonic interference and other human made noises do not dominate.

The induction fields of the ripple control signal must also be taken into consideration. The range of the induction fields is approximately one wavelength from the source (e.g. Wait, 1996 ), which is $\sim 300 \mathrm{~km}$ for $1050 \mathrm{~Hz}$; clearly, measurements of the radiation fields must be taken further than this from Dunedin.

Calculation of the ground fields were also computed using the FDTD method. Figure 4 shows the magnitude of the total radiated electric field calculated in the direction of the azimuthal maximum ( $40^{\circ}$ from North) at ground level. 
Comparing the results in Fig. 4 with the natural background noise it is clear that beyond the range of the induction fields, the electric field will not be measurable at any time. We find that the situation for magnetic fields is essentially identical. Hence, the radiation fields from the ripple control signal will not be measurable on the ground at any distance from Dunedin.

\subsection{Radiated power}

The vertical radiated power for our single dipole approximation was calculated by integrating the Poynting vector above the dipole. We calculate the total radiated power from the Dunedin $1050 \mathrm{~Hz}$ ripple control signal to be about $4 \mu \mathrm{W}$. Clearly, this radiated power is much lower than the $1 \mathrm{~W}$ triggering threshold found in active experiments (Helliwell et al., 1980), and thus the Dunedin ripple control signal is not a significant "pollutant" of geospace.

\subsection{Calculated fields above the ionosphere}

To estimate the ripple control radiation fields in geospace, we find the wavepower density at the base of the ionosphere, found using the electric and magnetic fields components calculated through the FDTD method. To find the absorption at satellite level we determine the attenuation the wave incurs as it propagates up to satellite altitude from the ionosphere base.

Given the local refractive index and wave power density the electric and magnetic field intensities can be calculated at any point using Maxwell's equations. We assume the radiated signal propagates in the whistler mode. Hence, the transmitted component of the incident wave on the ionosphere will propagate roughly vertically on entering the ionosphere. This allows us to use the simpler quasi-longitudinal approximation to the Appleton-Hartree equation (Helliwell, 1965). While our signal may not be propagating in the whistler mode, it will still undergo approximately the same attenuation as waves which are propagating in the whistler mode (Inan and Bell, 1977).

Our transmission losses on penetration into the lower ionosphere at $1050 \mathrm{~Hz}$ are based on Volland (1995), who present the coefficients for $1 \mathrm{kHz}$ at mid-latitudes. For vertically incident waves, the transmitted power decreases by approximately $7.0 \mathrm{~dB}$ at daytime and $5.3 \mathrm{~dB}$ at night, with respect to the incident power.

The wave power density undergoes absorption loss on propagation through the ionosphere, as described in Helliwell (1965). Integration of the imaginary component of the refractive index $\alpha$ over the propagation distance $h_{1}-h_{0}$ (in $\mathrm{m})$ will give the total absorption of the wave, such that

$A=8.69 \int_{h_{0}}^{h_{1}} \alpha \mathrm{d} h$

where 8.69 is the conversion factor from nepers to decibels. This integration requires profiles for the electron collision frequency, plasma frequency, and electron gyrofrequency.
An approximation to the electron collision frequency is given by Ratcliffe (1972),

$v=N_{n} \sigma \sqrt{\frac{3 k T}{m_{e}}}$

where $N_{n}$ is the neutral particle density, $\sigma=\pi\left(10^{-10}\right)^{2}$ is the collision cross-sectional area (Ratcliffe, 1972), $k$ the Boltzmann constant, $T$ the temperature and $m_{e}$ the electron mass. The plasma frequency and electron gyrofrequency depend on the electron density and the local magnetic field given by a simple dipole representation.

The electron density profile up to $1000 \mathrm{~km}$ altitude was taken from the International Reference Ionosphere (IRI) Bilitza (2001) standard model, allowing the calculation of the plasma frequency profile. Electron collision frequencies were determined from Eq. 2 using the Hedin (1991) atmospheric model, which provides the neutral particle temperature and density profile up to $1000 \mathrm{~km}$. Although our calculations take into account curved geomagnetic field lines, the profiles are strictly for the region vertically above Dunedin. This approximation will not change our results significantly.

We also consider the effect of irregularities in the ionosphere, consisting of depleted or enhanced ionisation levels in field aligned regions (e.g., Sonwalkar et al., 1984). A fairly extreme example would consist of an irregularity with a $20 \%$ ionisation difference (increase or decrease), starting at $200 \mathrm{~km}$ altitude. Using Snell's Law we estimate that such an irregularity would reduce the signal by about $2 \mathrm{~dB}$ at satellite altitudes in the worst case (for an ionisation enhancement), while in the best case the signal levels would be increased by about $3 \mathrm{~dB}$ (for an ionisation depletion).

With the profiles mentioned above, we evaluate Eq. (1) to satellite altitude $(710 \mathrm{~km})$ and add this to the Volland (1995) transmission loss on entry to the ionosphere. For vertically incident electromagnetic waves this gives a total absorption of $11.7 \mathrm{~dB}$ and $5.5 \mathrm{~dB}$ for day and night, respectively, allowing the calculation of the electric and magnetic fields using Maxwell's equations. Fig. 5 shows the electric and magnetic fields produced by Dunedin's ripple control signal at $710 \mathrm{~km}$ altitude. As expected the field strengths are strongly dependent upon the horizontal distance from Dunedin.

\subsection{Plasmaspheric noise levels}

For the ripple control radiation signal to be measurable at satellite altitudes the signal must be greater than the background plasmaspheric noise levels. One of our plasmaspheric noise estimates are based on the background noise levels below the ionosphere. We use the electric field noise values from Section 4.1 to find the power density, then we apply the absorption due to propagation through the ionosphere, as discussed in Section 4.3. This is likely to be provide an over-estimate of the noise levels, since not all the noise will propagate vertically. At winter until about $2000 \mathrm{LT}$ the atmospheric noise level at $1050 \mathrm{~Hz}$ at $710 \mathrm{~km}$ altitude becomes $0.02 \mu \mathrm{Vm}^{-1} \mathrm{~Hz}^{-\frac{1}{2}}$ and $3 \mathrm{fT} \mathrm{Hz}^{-\frac{1}{2}}$ for the electric 

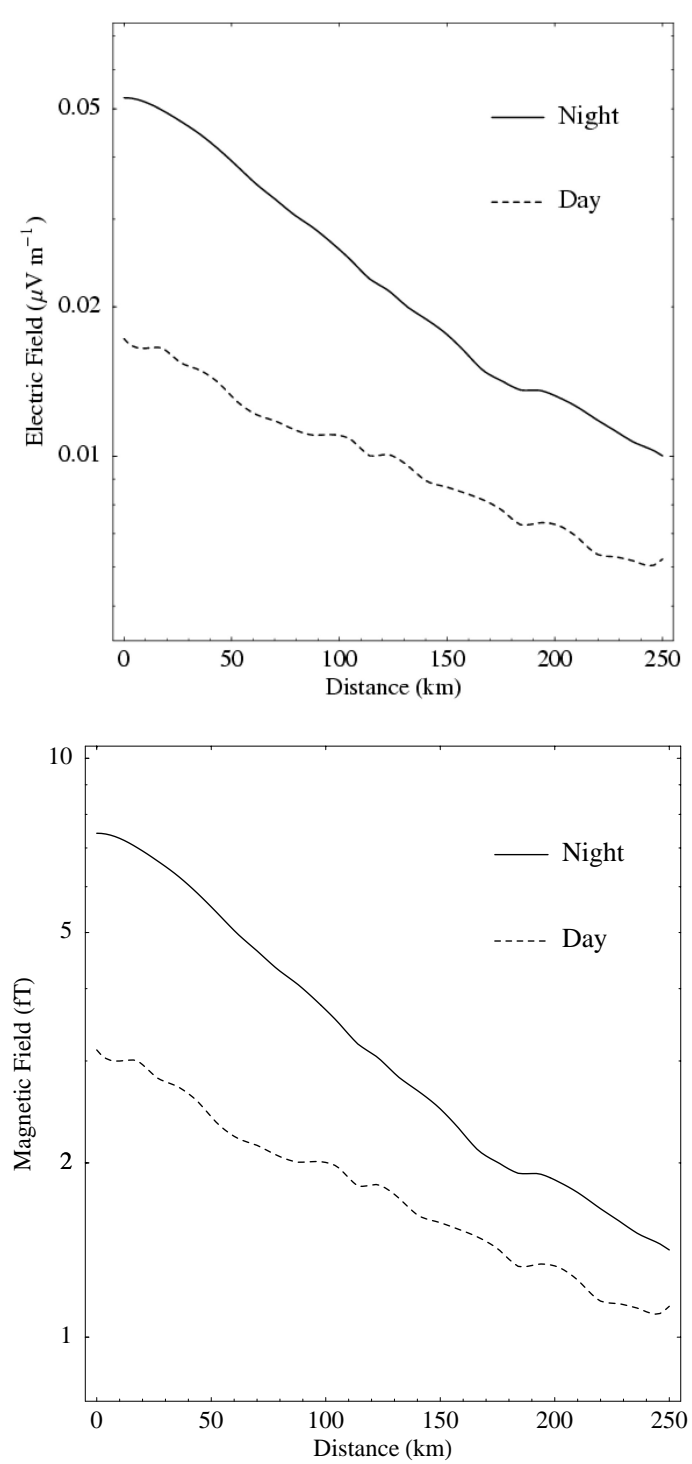

Fig. 5. The day and night electric and magnetic fields estimated due to radiation from Dunedin's ripple control signal. Calculated for an altitude of $710 \mathrm{~km}$ against increasing horizontal distance from the city centre.

and magnetic radiation fields, respectively. The atmospheric noise levels propagated though the winter nighttime ionosphere to $710 \mathrm{~km}$ altitude will be about the same at $2000 \mathrm{LT}$ as at midnight.

Previous observations by the AKEBONO (Exos-D) satellite provide higher values for the ambient background noise level within the plasmasphere, albeit in the polar region (Kasahara et al., 2001; Pickett et al., 1999). Although our study is concerned with mid-latitudes, we conservatively assume the background noise will be approximately the same. This should be an over-estimate since the polar regions generally tend to be "noisy" in comparison with mid and lowlatitudes. For quiet times the background magnetic field observed by Akebono at $1 \mathrm{kHz}$ is $\sim 0.1 \mathrm{pT} \mathrm{Hz}^{-\frac{1}{2}}$ (Kasahara
Table 1. Data for the DEMETER satellite (CNES, 2003).

\begin{tabular}{ll}
\hline Launch date & $29 \mathrm{June} 2004$ \\
Mass & $120 \mathrm{~kg}$ \\
Perigee & $710 \mathrm{~km}$ \\
Apogee & $720 \mathrm{~km}$ \\
Orbit period & $98.4 \mathrm{~min}$ \\
Data rate & $18 \mathrm{Mbps}(\max )$ \\
E field range & DC-3 MHz \\
E field sensitivity & $3 \mu \mathrm{V} \mathrm{m}-1 \mathrm{~Hz}^{-\frac{1}{2}}$ at $1 \mathrm{kHz}$ \\
B field range & $10 \mathrm{~Hz}^{-17.4 \mathrm{kHz}}$ \\
B field sensitivity & $5 \mathrm{fT} \mathrm{Hz}-\frac{1}{2}$ at $1 \mathrm{kHz}$ \\
\hline
\end{tabular}

et al., 2001). This is much greater than the estimate based on sub-ionospheric noise, as calculated above, due to source local to the plasmasphere.

The ambient plasmaspheric noise level at $1050 \mathrm{~Hz}$ should be in the range of the values discussed above.

\subsection{Equatorial field strengths}

From our radiation field calculations we can determine the fields in the equatorial region at satellite altitudes. Inan et al. (1984) and references therein provide an approach to calculate the wave power density anywhere along a field line in a slowly varying medium, assuming propagation in the ducted whistler mode. Inan et al. (1984) made radiation field calculations in the equatorial region for the Omega navigation VLF transmitter located in North Dakota (USA), and compared these with experimental observations. Although we make use of a more detailed ionospheric model than these authors, we calculate similar Omega transmitter field strengths to those reported. The ducted wave power density anywhere along the field line is found from

$P=\frac{P_{1} f_{H}}{f_{H 1}}$

where $P_{1}$ is the wave power in $\mathrm{Wm}^{-2}$ density at $1000 \mathrm{~km}, f_{H}$ and $f_{H 1}$ are the electron gyrofrequency, locally and at $1000 \mathrm{~km}$, respectively. The particle profile data described above allows these ionospheric properties to be calculated to $1000 \mathrm{~km}$. The electron gyrofrequency in the equatorial region for the $L=2.76$ value of Dunedin is about $71 \mathrm{kHz}$ (e.g. Helliwell, 1965). Thus we estimate that the wave power density in the equatorial region will be about $17.0 \mathrm{~dB}$ lower than at satellite level (shown in Fig. 5).

\section{Discussion}

We have estimated the radiation fields produced by the Dunedin ripple control signal at various altitudes. While the fields at ground level are not measurable, the radiation fields 
in the magnetosphere might be detected through satellite measurements. For example, the micro-satellite DEMETER, launched in June 2004 (CNES, 2003), carries instruments for measuring electric and magnetic fields, as described in Table 1.

In comparison with Fig. 5 and the instrument sensitivities given in Table 1 (using a $1 \mathrm{~Hz}$ bandwidth), we see that the electric fields due to the Dunedin ripple control signal will not be measurable by the satellite DEMETER as it passes near Dunedin. The peak electric field at night time conditions is well below the instrument signal detection threshold, nearly one hundred times lower when directly above Dunedin.

However, DEMETER's highly sensitive magnetic field detectors have a better chance for ripple control detection. A comparison with our magnetic field calculations (Fig. 5) with the sensitivities in Table 1 shows that DEMETER may be able to detect the signals up to $\sim 60 \mathrm{~km}$ during midnight ionospheric conditions. However, this is only true if there is was no other electromagnetic activity present. The midday ripple control signal will be below the instrument threshold. The detectable range would be increased by a marginal amount if the signal propagated to the satellite through a field aligned ionosation depletion.

Although the signal strength at DEMETER's altitude is greater than the instrument threshold, to be detectable it must also be greater than the ambient noise level. Using the noise levels discussed in Section 4.4 we see that the plasmasphere is going to have to be very "quiet" for detection of the Dunedin ripple control signal. For the lower noise estimate of $3 \mathrm{fT} \mathrm{Hz}^{-\frac{1}{2}}$ the ripple control radiation would have higher amplitudes than both the noise levels and the DEMETER sensitivities, but only for locations very near Dunedin. For the higher, albeit conservative "polar" noise level estimates, the ripple control radiation would not be observable for typical conditions. Unusually quiet conditions would be required.

Based on 21 days of DEMETER's orbit information (private communication, MichelParrot, 2003), we estimate that DEMETER will pass within $60 \mathrm{~km}$ of Dunedin approximately seven times per month. Statistically, this occurs about once every year during the standard 3 min ripple control operation. However, the Dunedin electricity supply utility has indicated that it may switch on some, or all of Dunedin's ripple control system, at specified times coinciding with the DEMETER satellite passing overhead.

It should be noted that existing databases of satellite measurements may already include the Dunedin ripple control signal. Other in situ satellites, such as EXOS-D (Nagano et al., 1991), may have already detected the ripple control signals in space.

There have been few attempts to measure the radiated fields on the ground from existing power lines. We have already mentioned the experimental campaign undertaken in Newfoundland (Yearby et al., 1983). Radiated fields were also measured from a $600 \mathrm{~km}$ High Voltage DC (HVDC) link operating between the South and North Islands of New Zealand (Barr, 1979). Observations of the HVDC signal were undertaken from three locations at distances from the base of the DC line of $\sim 70,110$, and $300 \mathrm{~km}$, respectively. A simple estimate suggested that this line should radiate $2 \mathrm{~W}$. However, the experimental measurements indicated that the radiated fields were $\sim 40$ times smaller. This discrepancy was explained by the presence of an earthed conductor running above and parallel to the entire HVDC line. Clearly, great care needs to be taken in considering the nature and layout of the electrical lines. If one neglected the existence of the current returning along the neutral line and had all the current in the ground return path, the radiated fields estimated in our calculations would be also be much higher than in the more realistic case.

\section{Conclusions}

The Dunedin city electrical network is tiny compared to the many large industrial zones found outside New Zealand. However, the $1050 \mathrm{~Hz}$ ripple control signal injected into the local electrical grid at regular intervals will produce active transmission to satellite altitudes radiated from a spatially well defined electrical network. The identification of $1050 \mathrm{~Hz}$ signals in satellite observations above Dunedin city during ripple control injection times would allow the clear identification of PLHR from a known source. This should allow a greater understanding of Power Line Harmonic Radiation (PLHR), and tests on the significance of man-made pollution to near-Earth space.

Calculations have been undertaken to estimate the strength of the radiation fields expected from the ripple control signal injected into the Dunedin city electrical network. Fields have been determined at ground level, the base of the ionosphere, satellite altitudes and in the equatorial plane in the magnetosphere. This has lead to the following conclusions:

1. The ripple control radiation fields will not be detectable above noise levels at ground-level, even during the "quietest" times.

2. The power radiated from the Dunedin ripple control signal is well below the reported threshold required for nonlinear triggering in the Van Allen radiation belts, as determined by Helliwell et al. (1980). Clearly the radiation from the ripple control signal is not a significant "pollutant" of geospace.

3. At the altitude of the DEMETER mission, detection of the radiated electric fields should not be possible under any ionospheric conditions. During midnight winter conditions the magnetic field will be above the instrument sensitivity at $60 \mathrm{~km}$ from Dunedin, but below atmospheric noise levels, making detection of the Dunedin ripple control signal very difficult. The magnetic field will be totally undetectable during daytime conditions at realistic satellite altitudes. 
Acknowledgements. The authors wish to thank K. Moffat of DELTA Utility Services Ltd for providing us with invaluable ripple control information and interesting tidbits during lunch meetings. We are also very grateful to M. Parrot of CNRS for supplying us with information on the DEMETER satellite. Also, S. M. Werner would also like the thank P. Murray for her ongoing support.

Topical Editor M. Pinnock thanks R. Dowden and M. Parrot for their help in evaluating this paper.

\section{References}

Abel, B. and Thorne, R. M.: Electron scattering loss in earth's inner magnetosphere -1 . Dominant physical processes, J. Geophys. Res., 103, 2385-2396, 1998.

Barr, R.: ELF radiation from the New Zealand power system, Planet. Space Sci., 27, 537-540, 1979.

Bilitza, D.: International reference ionosphere 2000, Radio Sci., 36, 261-275, 2001

Budden, K. G.: Radio waves in the ionosphere, Cambridge University Press, London, 1961.

Bullough, K.: Power line harmonic radiation: sources and environmental effects, in Handbook of Atmospheric Electrodynamics, 2, 291-332, CRC Press, Boca Raton, 1995.

Burke, G. J. and Poggio, A. J.: NEC user's guide, 1977.

CNES: Announcement of oppertunity, DEMETER, call for scientific reseach proposals, 2003.

Cummer, S. A.: Modeling electromagnetic propagation in the earthionosphere waveguide, IEEE Trans. Antennas Propagat., 48, 1420-1430, 2000.

Dunedin City Council: Electricity department, Dunedin City Council, Dunedin, 1971.

EASEINZ: Guide for the detection and measurement of harmonics in distribution networks, Electricity Supply Association of New Zealand, Wellington, 1989.

Farrel, W. M., Desch, M. D., and Houser, J. G.: Modification of the upper atmosphere over power lines: a geological effect, J. Geophys. Res., 103, 11 573-11 578, 1998.

Hedin, A. E.: Extension of the MSIS thermospheric model into the middle and lower atmosphere, J. Geophys. Res., 96, 1159-1172, 1991.

Helliwell, R. A.: Whistlers and related ionospheric phenomena, Stanford University Press, Stanford, 1965.

Helliwell, R. A., Carpenter, D. L., and Miller, T. R.: Power threshold for growth of coherent VLF signals in the magnetosphere, J. Geophys. Res., 85, 3360-3366, 1980.

Higuchi, H., Kimura, I., Hashimoto, K., Sato, N., and Tonegawa, Y.: Dependence of VLF wave activity at Syowa station on the day of the week, Mem. Natl. Inst. Polar Res. Spec. Issue Jpn., 42, 21-28, 1986

Inan, U. S. and Bell, T. F.: The plasmapause as a VLF wave guide, J. Geophys. Res., 82, 2819-2827, 1977.

Inan, U. S., Chang, H. C., and Helliwell, R. A.: Electron precipitation zones around major ground-based VLF signal sources, J. Geophys. Res., 89, 2891-2906, 1984.

Jenneson, J. R.: Electrical principles for the electrical trades, McGraw-Hill Book Company Australia, Roseville, second edn., 1987.

Kasahara, Y., Hosoda, T., Mukai, T., Watanabe, S., Kimura, I., Kojima, H., and Niitsu, R.: ELF/VLF waves correlated with transversely accelerated ions in the auroral region observed by Akebono, J. Geophys. Res., 106, 21 123-21 136, 2001.
Kraus, J. D.: Antennas, McGraw-Hill, New York, 2nd ed., 1988.

Nagano, I., Okada, T., Yamamoto, M., and Kimura, I.: Antenna vector impedance measurement by the EXOS-D (Akebono) very low frequency plasma wave instrument (VLF), Geophys. Res. Lett., 18, 313-316, 1991.

NZECP: NZECP 34:1993, New Zealand electrical code of practice for electrical safety distances, The Electricity Act 1992, 1993.

Park, C. G. and Chang, D. C. D.: Transmitter simulation of power line radiation effects in the magnetosphere, Geophys. Res. Lett., 5, 861-864, 1978 .

Parrot, M. and Zaslavski, Y.: Physical mechanisms of man-made influences on the magnetosphere, Survey in Geophysics, 17, 67100, 1996.

Parrot, M., Molchanov, O. A., Mogilevski, M. M., and Lefeuvre, F. Daily variations of ELF data observed by a low-altitude satellite, Geophys. Res. Lett., 18, 1039-1042, 1991.

Pickett, J. S., Gurnett, D. A., Menietti, J. D., LeDocq, M. J., Scudder, J. D., Frank, L. A., Sigwarth, J. B., Ackerson, K. L., Morgan, D. D., Franz, J. R., Kintner, P. M., Tsurutani, B. T., Ho, C. M., Chen, J., Fritz, T. A., Russell, C. T., Peterson, W. K., Kasahara, Y., Kimura, I., Watanabe, S., Arkos, G. G., Rostocker, G., Kokubun, S., Fukunishi, H., Pfaff, R. F., Mozer, F. S., Hsieh, S.-Y., Mukai, T., and Chandler, M. O.: Plasma waves observed during cusp energetic particle events and their correlation with Polar and Akebono satellite and ground data, Adv. Space Res., 24, 23-33, 1999.

Ratcliffe, J. A.: An introduction to the ionosphere and magnetosphere, Cambridge University Press, London, 1972.

Rennie, N.: Power to the people: 100 years of public electricity supply in New Zealand, Electricity Supply Association of New Zealand, Wellington, 1989.

Rodger, C. J., Clilverd, M. A., Yearby, K., and Smith, A. J.: Is magnetospheric line radiation man-made?, J. Geophys. Res., 105, 15 981-15 990, 2000

Rycroft, M. J.: Enhanced energetic electron intensities at $100 \mathrm{~km}$ altitude and a whistler propagating through the plasmasphere, Planet. Space Sci., 21, 239-251, 1973.

Smith, T. F.: Low-Frequency Radio Noise, in The handbook of atmospheric electrodynamics, vol. 1, CRC Press, Boca Raton, 1995.

Sonwalkar, V., Bell, T. F., Helliwell, R. A., and Inan, U. S.: Direct multiple path magnetospheric propagation - a fundamental property of nonducted vlf waves, J. Geophys. Res., 89, 2823-2830, 1984.

Stebbins, W. L.: A user's perspective on the selection and application of equipment and techniques to deal with harmonics and other power quality issues, Energy Eng., 93, 20-43, 1996.

Sullivan, D. M.: Electromagnetic simulation using the FDTD method, IEEE Press, New York, 2000.

Tomizawa, I. and Yoshino, T.: Power line radiation observed by the satellite "OHZORA", J. Geomagn. Geoelectr., 37, 309-327, 1985.

Tsurutani, B. T. and Lakhina, G. S.: Some basic concepts of waveparticle interactions in collisionless plasmas, Rev. Geophys., 35 , 491-501, 1997.

Volland, H.: Longwave sferics propagation within the atmospheric waveguide, in Handbook of Atmospheric Electrodynamics, 2, 65-93, CRC Press, Boca Raton, 1995.

Wait, J. R.: Electromagnetic waves in stratified media, IEEE Press in assoc. with Oxford University Press, New York, first published 1962, 1996. 
Walt, M.: Introduction to geomagnetically trapped radiation, Cambridge University Press, Cambridge, 1994.

Walt, M.: Source and loss processes for radiation belt particles, in Radiation Belts: Models and Standards, Geophys. Monogr. Ser., (Eds.) Lemaire, J. F., Heynderickx, D., and Baker, D. N., AGU, Washington, D.C., 97, 1-13, 1996.
Watt, A. D.: VLF radio engineering, Pergamon Press, 1967.

Yearby, K. H., A. J. Smith, T. R. K., and Bullough, K.: Power line harmonic radiation in Newfoundland, J. Atmos. Terr. Phys, 45, 409-419, 1983.

Young, J. L.: A full finite difference time domain implementation for radio wave propagation in a plasma, Radio Sci., 29, 1513$1522,1994$. 